\title{
AUTOMATIC COMPILATION \\ OF \\ MODERN CHINESE CONCORDANCES
}

\author{
Syunsuke UEMURA*, Yasuo SUGAWARA* \\ Mantaro J. HASHIMOTO**, Akihiro FURUYA***
}

\begin{abstract}
*E1ectrotechnical Laboratory, 1-1-4 Umezono, Sakura, Ibaraki 305, JAPAN
**Tokyo University of Foreign Studies, 4-51-21 Nishigahara, Kita, Tokyo 114, JAPAN

***Tokyo Metropolitan University, 1-1-1 Yakumo, Meguro, Tokyo 152, JAPAN
\end{abstract}

An automatic indexing experiment in Chinese is described. The first very large volume of modern Chinese concordances (two sets of one million-line KWIC index) has been compiled and materialized automatically with a modified kanji printer for Japanese.

\section{INTRODUCTION}

This paper describes an experiment to compile Chinese concordances automatically. A very large volume of KWIC indexes for modern Chinese (one million lines per set) has been compiled successfully with a kanji printer for Japanese. This paper discusses the purposes of the experiment, selection and input of the Chinese data, some statistics on Chinese characters (vs. kanji) and the concordance compilation process. Finally, examples from the computer-generated concordances are shown.

\section{THE PURPOSES}

The idea of machine-processing modern Chinese data originally came from Professor Yuen Ren Chao, Agassiz Professor Emeritus of Oriental Languages at the University of California at Berkeley, before one of the authors (Hashimoto) took over the directorship of the Princeton Chinese linguistics project. Chao served as the chief of the advisory committee to the project since its foundation. The idea, in short, was: so much has been said about the Chinese pai-hua-wen -- a written language of modern China -- yet nobody has ever clarified what it really was, i.e.; what the basic vocabulary was, what the major syntactic structure was, etc.: in other words the every detail of the reality of pai-hua-wen. Certain quantitative surveys were done before us, but even the most extensive one in those days was based on data consisting of no more than 100,000 characters. In addition, the selection was very poorly done -- most of the materials were primary school textbooks. We did not believe that school textbooks reflected the reality of the language, even in its written form. We chose one digit more than the previous one, namely $1,000,000$ characters, though for various reasons, the actual data contained in our tape include several thousands more than one mil1ion $[1,2]$.
After completion of the computer input and editing of the million-character file at Princeton, researches towards statistical aspects of the data have been conducted [4]. As stated in [4], tables of character frequency can tel1 us various aspects of the Chinese, such as the basic character set, transient states of character strings and so on. This can be summarized as the first step of computerprocessing modern Chinese data. However, in order to understand the reality of a language, besides statistics, concordances are the necessities which illustrate the contexts where and how those characters are used.

On the other hand, computer applications to Chinese have very limited background so for. No computer-generated concordances on Chinese have been reported yet. Thus the concordance genaration project would not on $1 y$ be valuable to the understanding of Chinese pai-hua-wen, but also contribute to the development of the methodology to manipulate Chinese automatically. Consequently, a project to compile concordances of the Princeton million-character file was conducted at the Electrotechnical Laboratory during 1977-1979. This constitutes the second important stage of computer-processing modern Chinese.

\section{THE CHINESE DATA}

\section{The Input of the Original Data}

The first phase of the data input was done in Taiwan during 1969-1972 with a Chinese character keyboard, designed by Cheng Chin Kao -- a Chinese teletype Machine (manufactured by the Oki Denki Co., Ltd.). The code was converted into the Chinese standard telegraphic code in Walthum, Massachusetts at a computer company. The greatest difficulty, in addition to ordinary proofreading, consisted in the conversion of the so-called "combination characters" of the C.C.Kao system: any character not found in the Kao keyboard was punched so that part of it (normally the "radical") was represented by a character having the same radical in the keyboard, and another by a character having the same "signific". Necessary flags were of course attached to these "combination characters", yet the key punchers selected those constituent characters quite at random, sometimes 
disregarding the position of a radical within a character, so that the results were often a hopeless mess.

The Selection of the Data

It was tried, at the selection of the data, to cover every conceivable category and style of writings in China since her modernization, the so-called May 5 Movement period, from ordinary novels to philosophical writings, from political speeches to newspaper articles, etc. etc. These categories and styles were classified and were assigned appropriate marks to show the genre. The partial list of these writings follow:

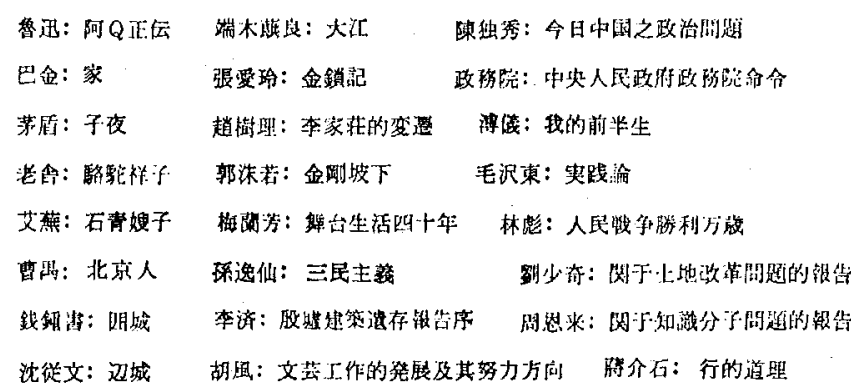

For a complete list of all these writings and of the genre marks, see [3]. A11 the proper nouns were so marked, as they may not correctly contribute to any statistical measurement of the written language except for these proper nouns themselves. These nouns were marked in the original texts by research assistants with enough command of the language to make correct judgment. Anything else, including punctuation marks of all sorts, in the texts were properly processed. Every sentence, including some vocative phrases, was numbered within the writing piece quite mechanicaly, though occasionally it was necessary for specialists to make certain judgment for segmenting sentences.

\section{The Code System}

The Chinese standard telegraphic code system includes some 9500 codes for Chinese characters. A code consists of a set of 4 digits, which represents one Chinese character. Among those 9500,5231 have been used.

\section{Statistics}

Statistical analysis of this million-character file can be found in [4]. Some additional statistics are provided here. Fig. 1 shows the 10 most frequent1y used characters with their frequencies. These 10 characters occupy $17.1 \%$ of the total amount. Fig. 2 is a table of character frequencies vs. the number of character types. Fig. 3 shows the cumulative percentage of character occurrences as a function of the number of character types (in descending order of frequency). It indicates, for example, only 92 characters represent $47 \%$ of the entire data. There are 1170 characters each of which are used more than 100 times and they occupy $92.8 \%$ of the whole data.

\begin{tabular}{cc} 
Character & Frequency \\
\hline 的 & 46531 \\
- & 18077 \\
是 & 17874 \\
3 & 16390 \\
不 & 16138 \\
我 & 12827 \\
在 & 11096 \\
人 & 11057 \\
有 & 10717 \\
他 & 10332 \\
\hline
\end{tabular}

Fig. 1. List of High Frequency Characters
No. of

Frequency Character Types

\begin{tabular}{rrr} 
& -10001 & 10 \\
$10000-5001$ & 13 \\
$5000-3001$ & 32 \\
$3000-2001$ & 37 \\
$2000-1001$ & 106 \\
$1000-501$ & 176 \\
$500-301$ & 208 \\
$300-201$ & 191 \\
$200-$ & 101 & 397 \\
$100-$ & 81 & 150 \\
$80-$ & 61 & 230 \\
$60-$ & 41 & 294 \\
$40-$ & 21 & 574 \\
$20-$ & 11 & 563 \\
$10-$ & 1 & 2250 \\
\hline
\end{tabular}

Fig. 2. Frequency Distribution of Chinese Character Types 


\section{CHINESE CHARACTERS VS. KANJI}

Chinese characters were imported into Japan sometime in the 5 th century. Since then, they have been extensively used with a few additional characters created in Japan (this modified set of Chinese characters is called "kanji"), although hiragana and katakana (two sets of pure Japanese characters with their origin also in the forms of Chinese characters) were invented early in the 9 th century.

"Chinese characters for daily use" established by the Ministry of Education for modern Japanese includes a $1850 \mathrm{kanji}$ set, however several thousand more are still in use especially for proper nouns. The Japanese Industria1 Standard (JIS) "Code of the Japanese Graphic Character Set for Information Exchange (C6226)" established in 1978 includes a 6349 kanji set, hiragana, katakana, Roman alphabet, Greek letters, Russian letters and other symbols. The kanji set is grouped into 2 levels, the first leve1 a 2965 kanji set and the second level a 3384 kanji set. This means some 3000 kanji are considered to be enough for basic information exchange in Japanese. In this experiment, the kanji printer system $\mathrm{T} 4100$

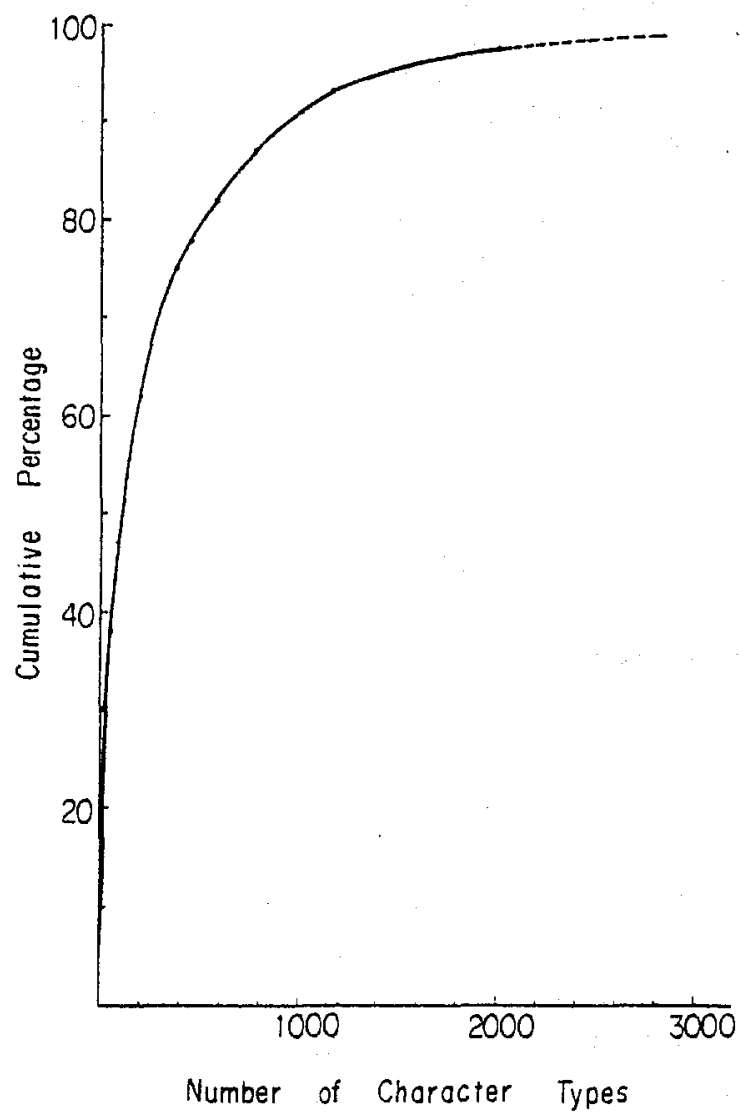

Fig. 3. Cumulative Percentage of Character Occurrences as a Function of the Number of Character Types
(Syowa Zyoho, Co., Ltd.) was used. A total of 8182 characters was available for this printer including 7360 kanji, hiragana, katakana, Roman alphabet, and other miscellaneous symbols. The system was developed 5 years before the establishment of JIS C6226.

As mentioned before, the million-character file included 5231 different Chinese characters. Among them, 295 were found to be unprintable (because they were not found in the T4100 system). The fonts of those 295 characters were designed and incorporated into the T4100 system. Later, when JIS C6226 was established, some of those 295 characters were found in the second level of the kanji set, namely 猫(frequency 773)，F彗(581)，黨(563)，随(345)，證(343)， 缺(189), 餘 (178), and 系( 158). Fig. 4 shows the frequency of the remaining 287 characters. Their total frequency numbers 1100 , which is $0.1 \%$ of the million-character file. This fact indicates that Chinese characters and kanji still overlap closely in modern Chinese and Japanese. (It should be noticed that the simplified Chinese characters are out of this scope since they did not exist at the so-called May 5 Movement period.)

\section{THE CONCORDANCES}

Besides the text itself, the Princeton millioncharacter file contained information on the title, the author, the sentence numbers, and other miscellaneous editorial symbols (such as

No. of

Frequency Character Types

$\begin{array}{cr}554 & 1 \\ 228 & 1 \\ 134 & 1 \\ 128 & 1 \\ 100-51 & 7 \\ 50-31 & 21 \\ 30-21 & 37 \\ 20-11 & 11 \\ 10-5 & 34 \\ 4 & 41 \\ 3 & 117 \\ 2 & \end{array}$

Fig. 4. Frequency Distribution of Chinese Characters which are not Found in the Kanji Set 
marks to indicate proper nouns). Extensive work had to be done to interpret and reform editorial symbols. Fig. 5 shows the edited text sentences from the million-character file. After this editorial step and incorporation of Chinese character fonts to the T4100 kanji printing ststem, the concordance compilation process was started. Since we have had experience with the automatic compilation of one-miliion line concordances in Japanese [5], not many technical difficulties were encountered, except some malfunctions of our old kanji printer. Discussions on the salient features of those Chinese concordances follow.

\section{Key Words}

KWIC index style has been adopted as the form of Chinese concordances, since it is one of the most fundamental styles for computer-generated concordances. Because there is no clear segmentation of words in Chinese, and because one character represents a fairly sizable amount of information, each character was chosen as a "key word". Furthermore, no elimination of "non-key words" were made. Every character (including punctuation) was chosen as a key character. In this sense, the concordance may be named as "Al1 characters in context" index. Consequently, one million character data required one million 1 ines of index.

\section{Contexts}

One of the deficiencies of the KWIC index style is that the context each line can show is

limited to its line length. We could afford 55 characters for the context. Since one or two Chinese characters represent a word, this length can accommodate more than 30 words of information in English.

\section{Reverse Sorted Index}

Two types of KWIC index have been produced. One is for the normal type, in which all lines are sorted in the ascending order of the Chinese standard telegraphic code of key characters (plus 7 succeeding characters). Fig. 6 shows an example page from this type of index. The other is the so called "reverse sorted" index. The major key for this type is the same as that of the normal type. The minor sort keys are, the characters immediately preceding the major key. Thus all lines for one key character are 1 isted in the ascending order of the code for the character immediately preceding the key character and so on. Fig. 7 shows an example page from the reverse sorted concordance.

\section{CONCLUDING REMARKS}

The two sets of modern Chinese concordances can be reached at the National Inter-university Research Institute of Asian and African Languages and Cultures, Tokyo University of Foreign Studies. It should be noted that a concordance of one million lines amounts to over 25,000 pages (actually it counts for 27,341) or 50 volumes of a $5 \mathrm{~cm}$-width paper file. Before printing the whole index, engineers recommended linguists to use COM technique, but in vain. A microfiche version should have been produced for portability. Analysis of the concordances have just got off the ground. The resulting papers are expected to follow.

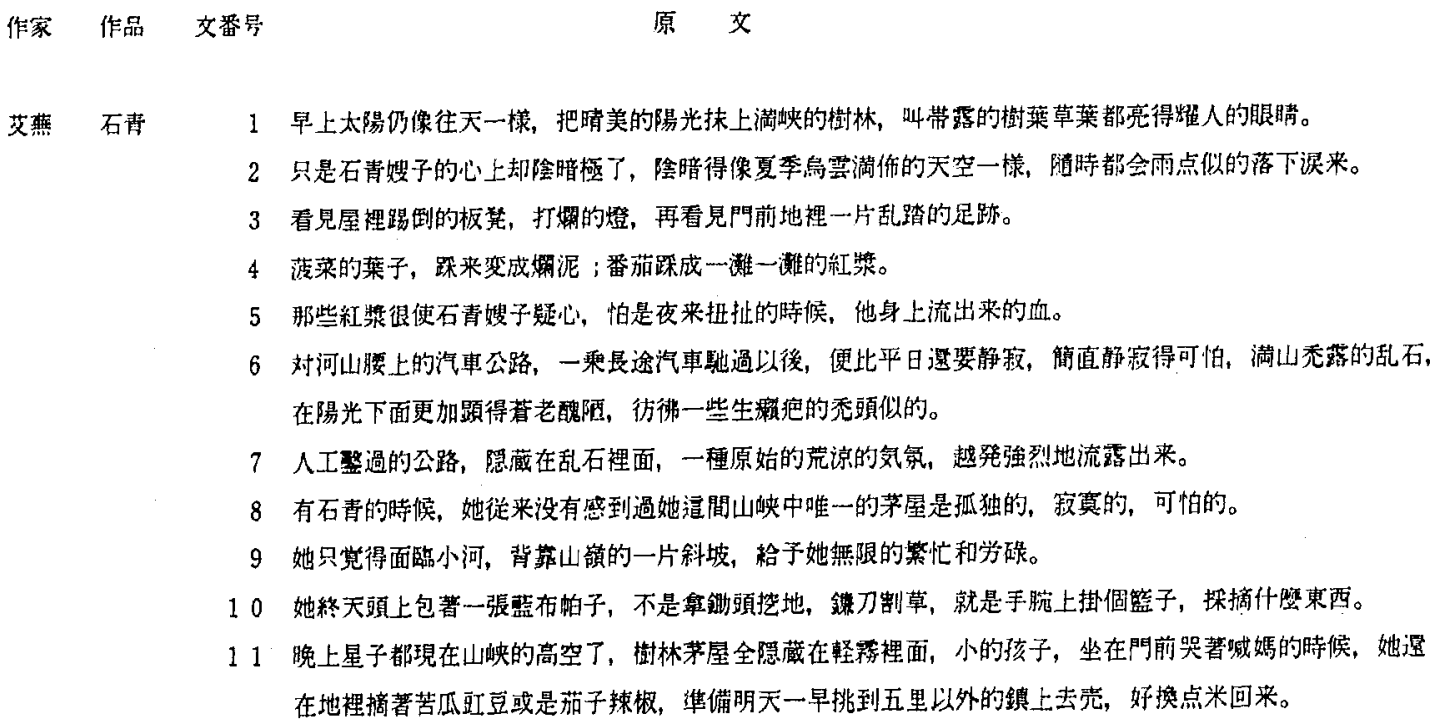

Fig. 5. An Example from the Edited Text 
，我国生産凘料所有制的社会主莫革命，已経基本完成。

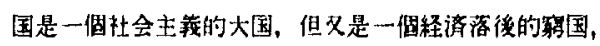

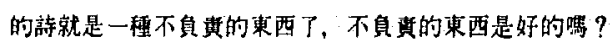

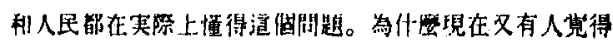

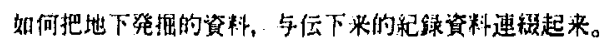

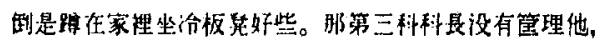

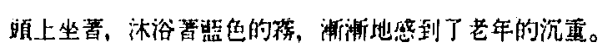

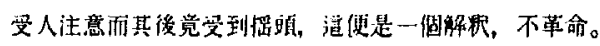

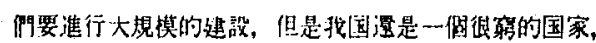

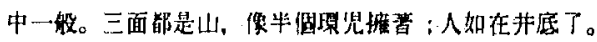
底变局。中国人本来城社人，到此時忽然成為郷下人了。

関於正確処理人民内部矛盾的問題， 表表示出来的。我們仍以下面道個三段唭定理為例QQ。

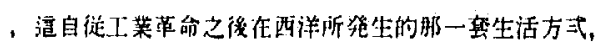

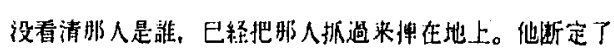

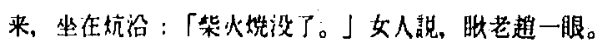

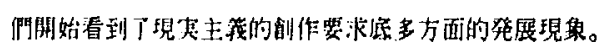

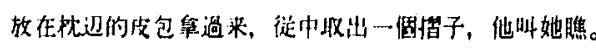

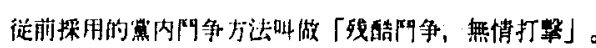

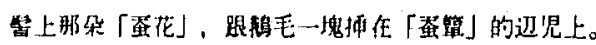
不坅撞著了一個巡路的小舆毛。当時没法，只好耛了他， 応」起来的。韓急談他自己做古文，「唯陳言之務去。」

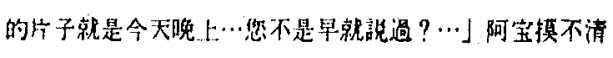

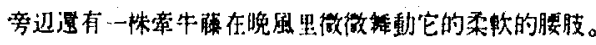
切胃你的時候，那就老得多了。」谓是一件很巧的事。厂

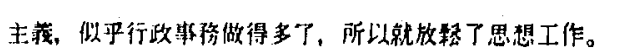

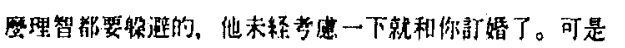

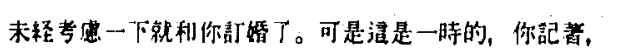

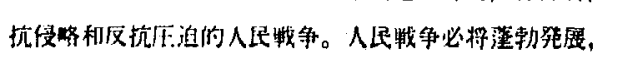

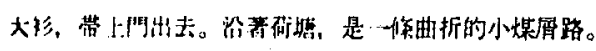

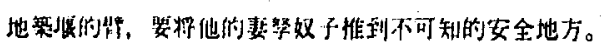

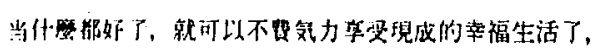

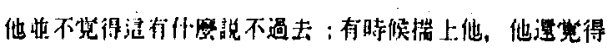

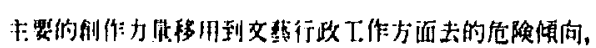

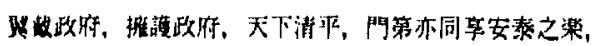

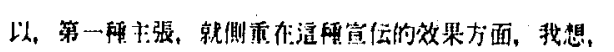

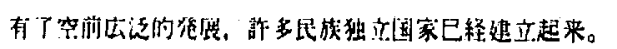

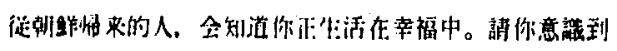

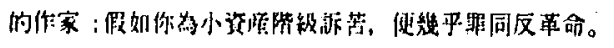

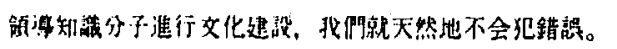

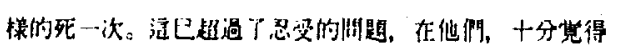

$$
6638 \text { 湆 (浔是一湴是) }
$$$$
-21944-
$$
$21944-$

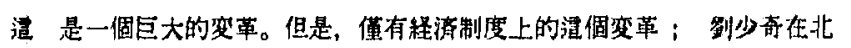
涼 是一個很大的矛盾。要使我国富強起来，需要幾十年熯苦 毛沢束関于

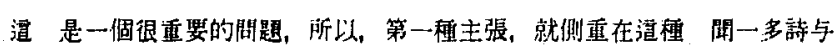

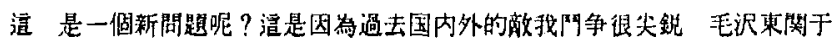
㴗 是一個业通的考占問題。也是在中国区域，考古家所面路 李済再談

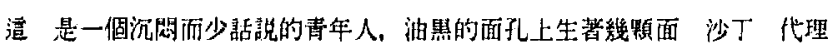

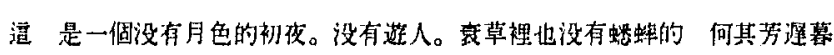

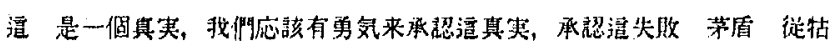

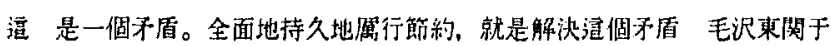

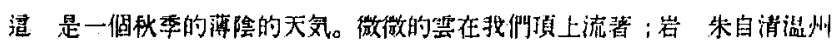

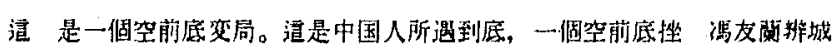
语 足一個総题目。為了涂述的方便，分為十二個小題目。在毛沢束関于

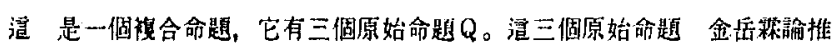

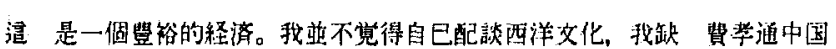

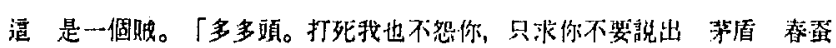

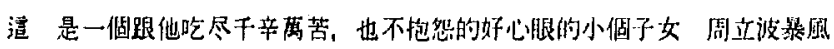

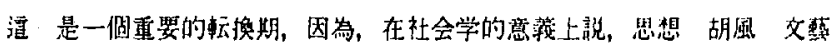

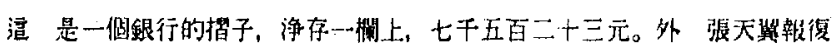

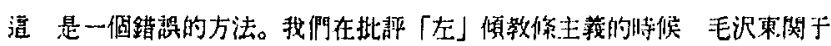

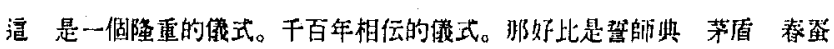

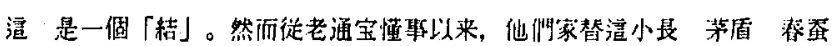

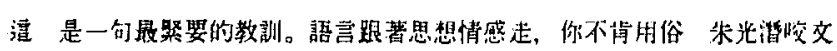

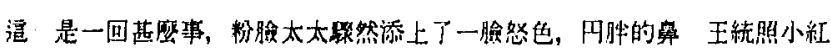

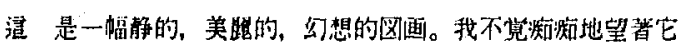
洁 是一张尺多宽的小小的㮛幅，馬孟容君画的。上方的左角 朱自清温州

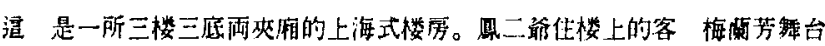
演 是一方面的理由，但不是全面的理由，甚至不是主荘的理 周掦 整頓

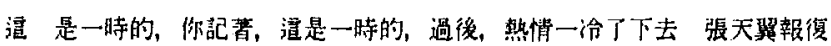

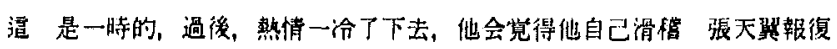

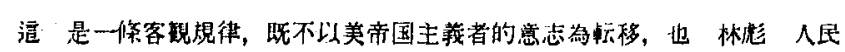

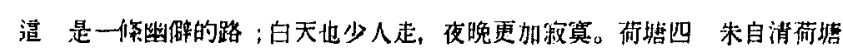

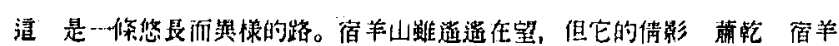
喓 是一種不実際的想法。我国少数民族有三千多萬人，踓然，

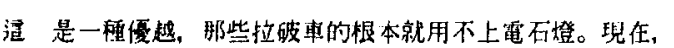
毛沢果関于 377

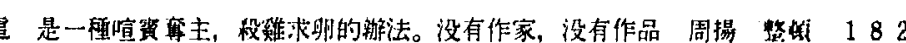

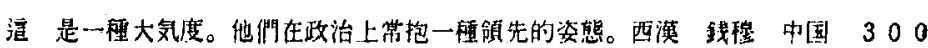

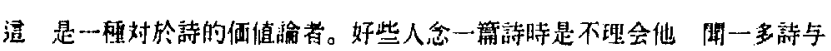
通是一程巨大的地界力量。一切被压迫民族的独立自主的要 梛少奇在北 19 33

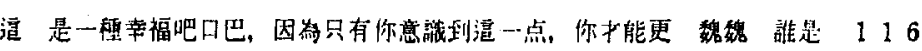

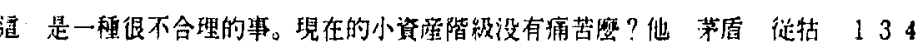
声 是一盘很危険的想法。而在有些地方，我們有一些同点正 周恩来関于 352 是一整恥繁。浔祼一直不会旱下去的，但是，他們等不得 端木良大江 89

Fig. 6. A Page Example from the Chinese Concordance (Normal Style) 


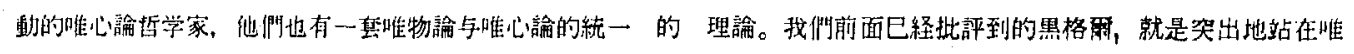

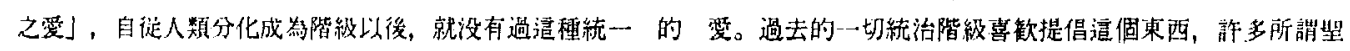

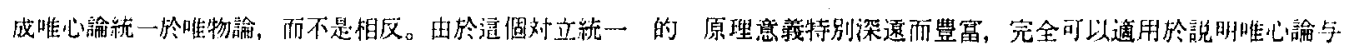

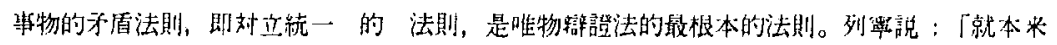

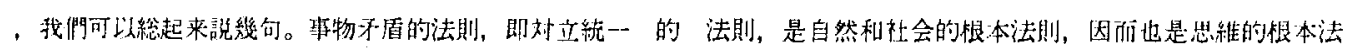

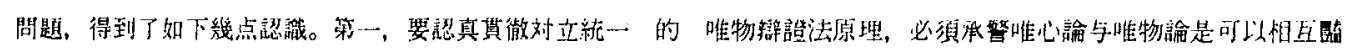

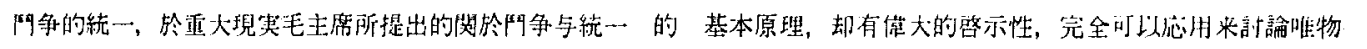

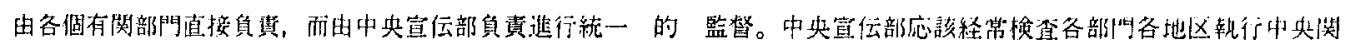
样㫮也是品的。現在是「陽春白雪」和「下里巴人」続一的

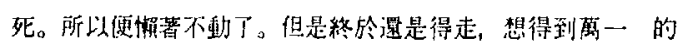

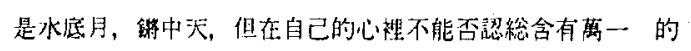

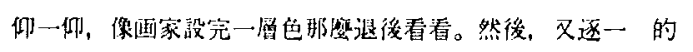

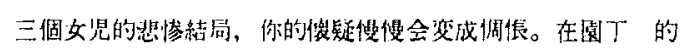
脸細盾，白浄皮色，太太模栐的女人，年紀不過二十六七的 声音乱叫了。但是那位作調人的餐察却洽笑，扳著陳老七的

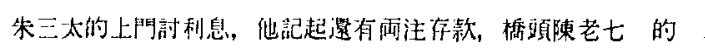
略影渾濁，有出山泉水的意思。若溯流淌上，則三大五文的

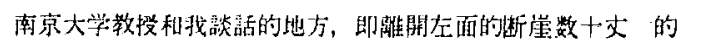

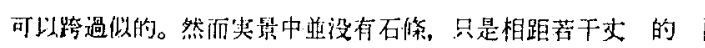

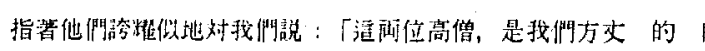
把著羊等，衰喚著「天妃」的意昘。我的心舟在起落萬文 的

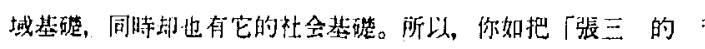

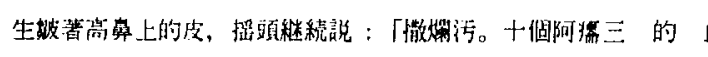
郷下你那些田，早早脱手得好。自從改了民国国，接二遇三的打俄

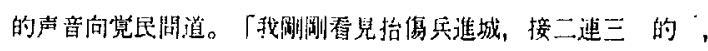

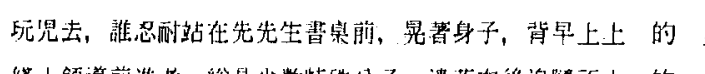

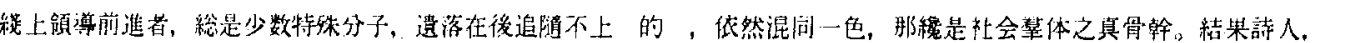

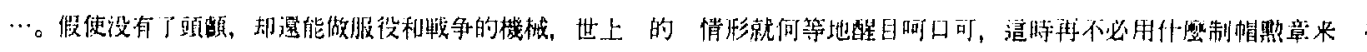

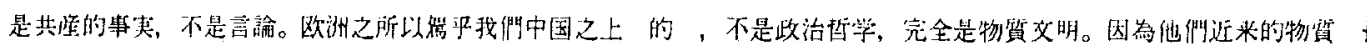

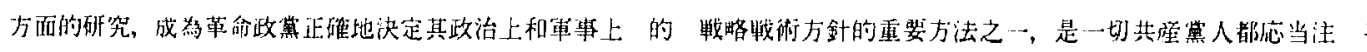

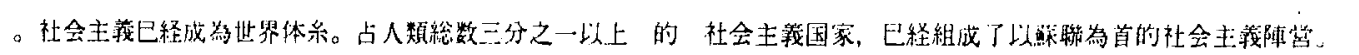

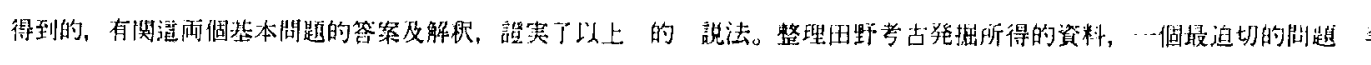

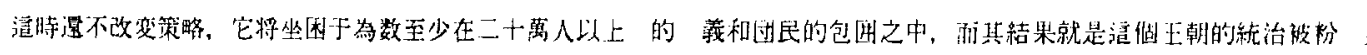

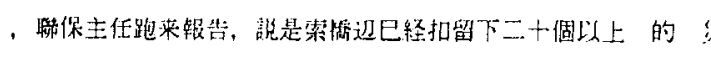

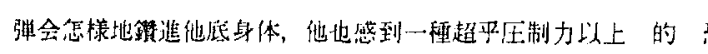

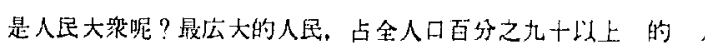

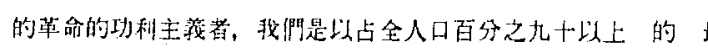

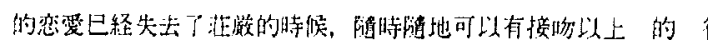
和他們在江北的地都管部在内，他們三家都有一千抬以上的如

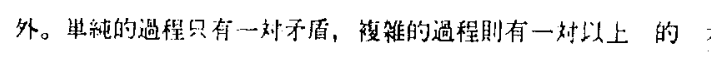
在小屯的建瑟遗址中，地基部份的夯士，有夯至十管以上的

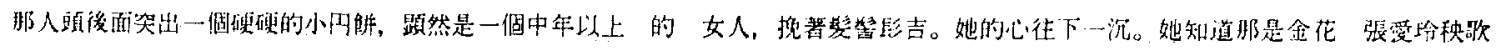

$$
\begin{gathered}
4104 \text { 的 (一的一上的) } \\
-16305-
\end{gathered}
$$

Fig. 7. A Page Example from the Chinese Concordance (Reverse Sorted Style) 


\section{REFERENCES}

1. Kierman, F.A. and Barber, E.: "Computers and Chinese linguistics", Unicorn, No. 3 (1968)

2. Boltz, W.G., Barber, E. and Kierman, F.A:

"Progress report on Pai-hua-wen computer count and analysis", Unicorn, No. 7, pp. 94-138 (1971)

3. Hashimoto, M.J., et a1.: A grammatical analysis of the Princeton million-character computer file", Bulletin of the Chinese Language Society of Japan, No.222, pp. $1-16,36$ (1975)

4. Hashimoto, M.J., : "Computer count of modern Chinese morphemes", Computational Analysis of Asian and African Languages, No. 7, pp. 29-41 (1977)

5. Uemura, S.: "Automatic Compilation and Retrieval of Modern Japanese Concordances", Journal of Information Processing, Vol. 1, No. 4, pp. 172-179 (1979) 